\title{
Perbandingan Kecukupan Asi Ibu Menyusui Antara Konsumsi Ekstrak Daun Kelor Dengan Konsumsi Ekstrak Biji Fenugreek
}

\author{
Nur Khasanah ${ }^{1)}$, Anita Liliana ${ }^{2)}$,Claresta Jessy Widia Sandra ${ }^{3)}$ \\ ${ }^{1,2,3}$ Fakultas Ilmu Kesehatan, Universitas Respati Yogyakarta \\ Email : Nurkhasanah@respati.ac.id
}

Diterima: November 2021, Diterbitkan: desember 2021

\begin{abstract}
Abstrak
Pemenuhan gizi bayi usia 0-6 bulan merupakan suatu hal yang sangat pentingdan hanya dapat diperoleh melalui pemberian ASI Eksklusif, sehingga ibu menyusui membutuhkan tambahan nutrisi sebanyak 400$500 \mathrm{Kkal}$ setiap harinya. Ibu membutuhkan tambahan kandungan nutrisi yang mampu meningkatkan produksi ASI seperti laktogogum dan flavonoid pada daun kelor dan biji fenugreek, akan tetapi Sebagian besar masyarakat belum mengetahui hal tersebut. Padahal Potensi sumber daya alam sangat melimpah dengan manfaat yang luar biasa seperti manfaat daun kelor dan biji fenugreek. Penelitian ini bertujuan untuk mengetahui perbedaan kecukupan ASI antara ibu yang mengkonsumsi ekstrak daun kelor (moringa oleifera) dengan ekstrak biji fenugreek (trigonella foenum-graecum) di wilayah kerja puskesmas linggang bigung. Desain penelitian ini adalah quasi Experiment dengan rancangan post test-only without control group design. Jumlah sampel $32 \mathrm{ibu}$ post partum diambil dengan teknik purposive sampling. Analisis bivariate yang digunakan ialah Two Way Anova. Hasil penelitian menunjukkan kecukupan ASI pada kelompok ekstrak daun kelor 15 (93,75\%) sedangkan kecukupan ASI pada kelompok ekstrak biji fenugreek 14 (87,5\%). Tidak ada perbedaan yang signifikan antara ekstrak daun kelor dan ekstrak biji fenugreek terhadap kecukupan ASI pada ibu menyusui di wilayah kerja puskesmas linggang bigung, dengan nilai significancy pada hasil menunjukan $(p=0.559>0.05)$
\end{abstract}

Kata kunci : Ekstrak Daun kelor, Ekstrak Biji Fenugreek, Kecukupan ASI

\begin{abstract}
Nutrition Fulfillment for infants aged 0-6 months is essential, it can only be obtained through exclusive breastfeeding. The extent of exclusive breastfeeding coverage is influenced by the mothers' nutritional adequacy. Breastfeeding mothers need an additional 400-500 kcal of nutrients per day. In addition to highcalorie foods, mothers also need additional nutritional content that can increase breast milk production, such as lactogogum and flavonoids contained in Moringa leaves and fenugreek seeds. The potential of abundant natural resources with extraordinary benefits such as the benefits of Moring leaves and fenugreek seeds are not yet known by the public, including its benefits in increasing breast milk production. This study aims to determine the difference in breast milk adequacy between mothers who consume Moringa leaf extract (moringa oleifera) and mothers who consume fenugreek seed extract (Trigonella foenum-graecum) in 'Linggang Bigung' Community Health Center work area. This research has a quasi-experimental format with a post-test-only without control group design. This study involves 32 post-partum mothers as samples. The research data is collected using a non-probability sampling with a purposive sampling technique. Bivariate analysis used in this study is Two Way Anova. Breast milk adequacy is found in 15 respondents in the Moringa leaf extract group (93.75\%), while in the fenugreek seed extract group, 14 respondents (87.5\%). There is no significant difference between the effects of Moring leaf extract and fenugreek seed extract on breast milk adequacy in breastfeeding mothers in Linggang Bigung Community Health Center
\end{abstract}


work area, with a significance value in the results showing $p=0.559>0.05$.

Keywords: Moringa leaf extract, Fenugreek seed extract, Breast milk adequacy

\section{PENDAHULUAN}

Pemenuhan gizi bayi usia 0-6 bulan merupakan suatu hal yang sangat penting dalam menunjang tumbuh kembang bayi, yang mana gizi tersebut hanya dapat diperoleh melalui ibunya dengan cara pemberian ASI Eksklusif (Zakaria Z. dkk, 2016), namun hingga saat ini cakupan pemberin ASI di Indonesia masih rendah jika dibandingkan dengan tahun 2018 yaitu $68,74 \%$ (Kemenkes, 2018) menurun menjadi 64,74\% pada tahun 2019 (Kemenkes, 2019), padahal target nasional pemberian ASI di Indonesia yang telah ditetapkan oleh pemerintah melalui Peraturan Pemerintah No.33 Tahun 2012 adalah seluruh bayi yang dilahirkan harus diberikan ASI Eksklusif sehingga secara tidak langsung bahwa pemerintah menargetkan cakupan pemberian ASI yaitu 100\% (Presiden RI, 2012). Peraturan tersebut dibuat tidaklain karena pentingnya dan begitu besarnya manfaat pemberian ASI secara eksklusif, dan apabila bayi tidak mendapatkannya maka bayi akan lebih cenderung mudah terkena penyakit seperti diare, daya tahan tubuh bayi yang lemah, bahkan gizi buruk serta perkembangan otak terganggu sehingga dapat menyebabkan kecerdasan yang menurun jika dibandingkan dengan anak yang di berikan ASI ekslusif (Mufdillah. Dkk, 2017) serta angka kejadian mortalitas lebih tinggi terjadi pada bayi yang tidak diberikan ASI Ekslusif dibandingkan dengan bayi yang di beri ASI Ekslusif (Adi. G. S, 2019)

Keberhasilan pemberian ASI secara eksklusif sangat ditentukan oleh kelancaran produksi ASI dan pengeluaran ASI, yang mana kedua hal tersebut dipengaruhi oleh kinerja hormone prolaktine dan hormone oksitosin dalam tubuh, kedua hormone tersebut dapat bekerja secara efektif apabila kebutuhan nutrisi ibu selama menyusui tercukupi tidak hanya dari segi kuantitas tetapi juga kualitas makanan yang dikonsumsi. Sehingga kebutuhan nutrisi ibu sejak hamil hingga menyusui perlu diperhatikan oleh ibu itu sendiri, akan tetapi masih banyak ibu yang belum memahami hal tersebut dan tidak mengetahui kebutuhan nutrisi ibu selama menyusui (Mustika \& Nurjanah, 2018)

Ibu menyusui membutuhkan tambahan energy sebesar 400-500 Kkal setiap hari yang dapat diperoleh dari berbagai sumber bahan makanan, khususnya makanan tidak hanya tinggi kalori, tetapi juga memiliki berbagai kandungan nutrisi yang dibutuhkan dalam meningkatkan produksi ASI seperti laktogogum dan kandungan flavonoid pada daun kelor dan biji fenugreek. Kedua tanaman tersebut memiliki total $205 \mathrm{Kkal}$ kalori pada daun kelor sedangkan pada biji fenugreek terdapat $323 \mathrm{Kkal}$ serta kandungan vitamin, mineral, serat, dan karbohidrat yang mampu memenuhi kebutuhan harian ibu (Kemenkes, 2019)

Potensi sumber daya alam yang melimpah dengan manfaat yang luar biasa seperti manfaat daun kelor dan biji fenugrek yang belum diketahui oleh masyarakat, termasuk manfaatnya dalam meningkatkan produksi ASI. tanaman kelor sendiri mengandung senyawa fistosterol yaitu alkaloid, saponin dan flavonoid yang mampu meningkatkan hormone prolaktin agar meningkatkan produksi ASI dan merangsang hormon oksitosin untuk mengeluarkan ASI (Indri Pratiwi, M. S. 2020) Serta efek laktogogum yang dipercaya mampu meningkatkan produksi dan pengeluaran ASI pada ibu menyusui (Kristina, N. N., \& Siti, F. S. 2014). begitupun dengan Biji Fenugreek adalah salah satu tanaman galaktogoga yang memiliki kandungan asam amino, serat, 
mineral, trigonelline, kolin, prolamin, sapogenin, alkaloid dan serat sapogenin (Karima, N.,dkk. 2020) dan yang terpenting adalah kandungan senyawa flavonoid yang mampu meningkatkan hormone prolaktin yang meningkatkan produksi ASI dan merangsang hormon oksitosin untuk mengeluarkan ASI (Okinarum, G. Y, dkk. 2020)

\section{METODE}

Jenis penelitian yang digunakan pada penelitian ini Penelitian kuantitatif, menggunakan desain penelitian quasi Experiment dengan rancangan post test-only without control group design dengan responden berjumlah $32 \mathrm{ibu}$ post partum yang di bagi menjadi dua kelompok, yaitu $16 \mathrm{ibu}$ dalam kelompok intervensi konsumsi Ekstrak Daun kelor dan 16 ibu dalam kelompok intervensi Ekstrak biji fenugreek. Sebelum melakukan intervensi peneliti mengajukan etical clearance kepada Komisi Etik dan disetujui pada tanggal 16 Juli 2021, selanjutnya peneliti mengurus surat izin penelitian ke Dinas Kesehatan setempat dan mulai berkoordinasi dengan para Bidan yang membuka praktik di Wilayah Kerja Puskesmas Linggang Bigung untuk meminta bantuan sebagai Asisten peneliti sehingga pada saat ada partus peneliti segera melakukan intervensi setalah mendapat persetujuan dari responden dengan bukti penandatanganan informed consent. Setelah menetapkan sample peneliti mulai memberi perlakuan baik itu perlakuan Ekstrak Daun kelor maupun ekstrak biji fenugreek sebanyak 2 tablet/hari (pagi dan sore hari) dengan dosis $500 \mathrm{mg} /$ tablet selama tujuh hari, pengukuran dilakukan pada hari kedelapan dengan melihat tanda-tanda kecukupan ASI pada bayi melalui kuisioner dan lembar observasi. Setelah data terkumpul dilakukan pengolahan dan analisis data menggunakan uji Anova two way.
HASIL DAN PEMBAHASAN

Pada kelompok ekstrak daun kelor ibu yang memiliki ASI yang cukup sebanyak 15 $(93,75 \%)$ sedangkan pada kelompok yang diberikan ekstrak biji fenugreek yang memiliki ASI yang cukup sebanyak 14 $(87,5 \%)$. Tidak ada perbedaan yang signifikan antara ekstrak daun kelor dan ekstrak biji fenugreek terhadap kecukupan ASI pada ibu menyusui di wilayah kerja puskesmas linggang bigung, dengan nilai significancy pada hasil menunjukan $(p=0.559>0.05)$.

Tabel 1 Karakteristik Responden

\begin{tabular}{|c|c|c|c|}
\hline Keterangan & & frekuensi & $\begin{array}{c}\text { Presentase } \\
\%\end{array}$ \\
\hline \multirow[t]{2}{*}{ Usia } & $<20$ tahun & 3 & 9.4 \\
\hline & 20-35 tahun & 29 & 90.6 \\
\hline \multirow[t]{2}{*}{ Pekerjaan } & IRT & 19 & 59.4 \\
\hline & Swasta & 13 & 40.6 \\
\hline $\begin{array}{l}\text { Pola } \\
\text { istirahat }\end{array}$ & $\begin{array}{l}\text { Ibu tidur }<7 \\
\text { jam dimalam }\end{array}$ & & \\
\hline \multirow{2}{*}{$\begin{array}{l}\text { Di malam } \\
\text { hari }\end{array}$} & hari & 15 & 46.9 \\
\hline & $\begin{array}{l}\text { Ibu tidur } 7 \text { jam } \\
\text { dimalam hari }\end{array}$ & 17 & 53.1 \\
\hline \multirow{2}{*}{$\begin{array}{l}\text { Pola } \\
\text { istirahat } \\
\text { Di siang } \\
\text { hari }\end{array}$} & $\begin{array}{l}\text { Saat bayi tidur } \\
\text { di siang hari ibu } \\
\text { juga tidur }\end{array}$ & 26 & 81.3 \\
\hline & $\begin{array}{l}\text { Saat bayi tidur } \\
\text { di siang hari ibu } \\
\text { tidak tidur }\end{array}$ & 6 & 18.8 \\
\hline \multirow[t]{3}{*}{ Paritas } & Primipara & 11 & 34.4 \\
\hline & Multipara & 10 & 31.3 \\
\hline & Grademultipara & 11 & 34.4 \\
\hline
\end{tabular}

Berdasarkan tabel 1 didapatkan karakteristik jumlah usia terbanyak dalam penelitian ini berada pada usia produktif di yaitu pada usia 20-35 tahun sebanyak 29 orang $(90.6 \%)$. Pekerjaan terbanyak yang di lakukan oleh responden adalah sebagai Ibu Rumah Tangga (IRT) sebanyak 19 orang $(59.4 \%)$. Pola istirahat terbagi menjadi dua yaitu pola istirahat ibu di malam hari dan istirahat di siang hari dimana pada malam hari ibu lebih banyak ibu yang tidur 7 jam 
dimalam hari sebanyak 17 orang (53.1\%). Sedangkan untuk pola istirahat di siang hari lebih banyak ibu yang saat bayinya tidur ibu juga tidur sebanyak 26 orang $(81.3 \%)$. Dan untuk paritas pada penelitian ini didapatkan karakteristik jumlah banyaknya persalinan yaitu primipara dan grademultipara masingmasing 11 orang (34.4\%).

Tabel 2 Kecukupan ASI pada kelompok yang diberikan ekstrak daun kelor 4.2

Tabel Kecukupan ASI pada kelompok ekstrak daun kelor

\begin{tabular}{|c|c|c|c|c|c|c|}
\hline \multirow{3}{*}{$\begin{array}{c}\text { Konsums } \\
\text { i ekstrak }\end{array}$} & \multicolumn{6}{|c|}{ Kecukupan ASI } \\
\hline & \multicolumn{2}{|c|}{ Cukup } & \multicolumn{2}{|c|}{$\begin{array}{l}\text { Tidak } \\
\text { cukup }\end{array}$} & \multicolumn{2}{|c|}{ total } \\
\hline & $\mathrm{N}$ & $\%$ & $\mathrm{~N}$ & $\%$ & $\mathrm{~N}$ & $\%$ \\
\hline $\begin{array}{c}\text { Ekstrak } \\
\text { daun } \\
\text { kelor }\end{array}$ & 15 & $93,75 \%$ & 1 & $6,25 \%$ & 16 & 100.0 \\
\hline
\end{tabular}

Berdasarkan tabel 2 didapatkan hasil bahwa Sebagian besar ibu yang diberikan ekstrak daun kelor kecukupan ASI nya dalam kategori cukup yaitu berjumlah 15 ibu $(93,75 \%)$.

Tabel 3 Kecukupan ASI pada kelompok yang di berikan ekstrak biji fenugreek 4.3

Tabel kecukupan ASI pada kelompok ekstrak biji fenugreek

\begin{tabular}{|c|c|c|c|}
\hline \multirow{3}{*}{$\begin{array}{l}\text { Konsums } \\
\text { i ekstrak }\end{array}$} & \multicolumn{3}{|c|}{ Kecukupan ASI } \\
\hline & cukup & $\begin{array}{l}\text { Tidak } \\
\text { cukup }\end{array}$ & Total \\
\hline & $\%$ & $\mathrm{~N} \%$ & $\%$ \\
\hline
\end{tabular}

\begin{tabular}{crrrrrr}
\hline Ekstrak & 14 & 87, & 2 & 12, & 16 & 100.0 \\
biji & & $5 \%$ & & $5 \%$ & & \\
fenugree & & & & & & \\
k & & & & & & \\
\hline
\end{tabular}

Berdasarkan tabel 3 didapatkan hasil bahwa Sebagian besar ibu yang diberikan ekstrak biji fenugreek kecukupan ASI nya dalam kategori cukup yaitu berjumlah $14 \mathrm{ibu}$ $(87,5 \%)$.
Tabel 4 hasil uji perbandingan antara ekstrak daun kelor dengan ekstrak biji fenugreek terhadap kecukupan ASI

\begin{tabular}{cccc}
\hline $\begin{array}{c}\text { Kecukupan } \\
\text { ASI }\end{array}$ & mean & Std.error & Sig \\
\hline $\begin{array}{c}\text { Ekstrak } \\
\text { daun kelor }\end{array}$ & 1.063 & 0.075 & 0.559 \\
$\begin{array}{c}\text { Ekstrak biji } \\
\text { fenugreek }\end{array}$ & 1.125 & 0.075 & \\
& & &
\end{tabular}

Berdasarkan tabel 4 didapatkan didapatkan nilai mean antara ekstrak daun kelor dan ekstrak biji fenugreek $1.063<1.125$ maka dapat di simpulkan bahwa ekstrak daun kelor memiliki potensi yang lebih tinggi dalam pemenuhan kecukupan ASI, dimana nilai data yang lebih kecil kecil merupakan indikasi bahwa data refresentatif. Data refresentatif adalah sampel yang benar-benar dapat mewakili dari seluruh populasi. Serta untuk nilai sig $0.559>0.05$ maka dapat di simpulkan bahwa tidak ada perbedaan yang signifikan antara kelompok yang mengkonsumsi ekstrak daun kelor dan kelompok yang mengkonsumsi ekstrak biji fenugreek kedua ekstrak ini sama-sama mampu memenuhi kecukupan ASI.

Kedua ekstrak ini sama-sama merupakan tanaman galaktogoga, tanaman galaktogoga dapat digunakan untuk merangsang dan meningkatkan produksi ASI. Selain itu daun kelor maupun biji fenugreek sama- sama memiliki kandungan flavonoid yang memiliki potensi merangsang hormone Prolaktin dan Oksitosin yang meningkatkan produksi ASI sehingga mampu memenuhi kecukupan ASI pada ibu menyusui hal ini lah yang membuat kedua kelompok sama-sama mampu memenuhi kecukupan ASI pada ibu menyusui.

Setelah mengkonsumsi ekstrak daun kelor maupun ekstrak biji fenugreek dalam waktu 24 jam pada kelompok yang mengkonsumsi ekstrak daun kelor maupun kelompok yang mengkonsumsi ekstrak biji 
fenugreek sebagian besar ibu mengalami peningkatan produksi ASI, sampai terus berlanjut hingga hari ke tujuh produksi ASI ibu terus meningkat dan membantu ibu dalam memenuhi kecukupan ASI. Setelah ASI lancar, pengonsumsian ekstrak di hentikan karena apabila terus di konsumsi memiliki beberapa efek samping diantaranya pada kelompok yang mengkonsumsi ekstrak daun kelor jika di konsumsi secara berlebihan makan dapat mengakibatkan diare pada ibu maupun bayi, pada daun kelor sendiri memiliki kandungan laksatif atau pencahar. Namun pada penelitian ini tidak terdapat efek samping yang terjadi pada ibu maupun bayinya karena ekstrak yang dikonsumsi sesuai dengan anjuran dan SOP.

Sedangkan pada kelompok yang mengkonsumsi ekstrak biji fenugreek jika ekstrak tersebut dikonsumsi secara berlebihan dapat menyebabkan bau urin yang menyengat seperti bau mapel, keringat berlebih serta diare karena biji fenugreek juga memiliki kandungan laksatif atau pencahar yang dapat mengakibatkan diare pada ibu maupun bayinya jika ekstrak biji fenugreek di gunakan secara berlebihan. Namun pada penelitian ini tidak terdapat efek samping yang terjadi pada ibu maupun bayinya karena ekstrak yang dikonsumsi sesuai dengan anjuran dan SOP.

\section{KESIMPULAN DAN SARAN}

Tidak terdapat perbedaan yang signifikan antara kelompok yang di beri ekstrak daun kelor dengan kelompok yang diberi ekstrak biji fenugreek, kedua ekstrak ini sama-sama mampu dalam hal memenuhi kecukupan ASI.

Disarankan untuk menggunakan responden yang lebih banyak lagi agar mendapatkan hasil yang lebih maksimal. Serta dapat melakukan observasi setiap harinya untuk melihat perbedaan yang dialami oleh responden dan mendapatkan hasil yang lebih maksimal.
Bagi institusi bisa menjadikan hasil penelitian ini sebagai tambahan kepustakaan sebagai sumber penelitian terkait penelitian tentang penggunaan ekstrak bahan herbal (daun kelor dan biji fenugreek) guna melestarikan tanaman herbal yang ada di sekitar kita untuk memenuhi kecukupan ASI ibu menyusui.

Di sarankan bagi ibu, harus tau bagaimana cara mengatasi masalah dalam hal memenuhi kecukupan ASI dengan pemanfaatan tanaman lokal seperti (ekstrak daun kelor atau ekstrak biji fenugreek) yang mampu meningkatkan produksi ASI dan mampu memenuhi kecukupan ASI pada ibu dan bayi. Selain pemanfaatan tanaman lokal ibu juga bisa memenuhi kecukupan ASI dengan cara rajin melakukan perawatan payudara (Breast Care) serta pemijatan payudara.

Di sarankan bagi tenaga kesehatan lebih aktif dalam memberikan pendidikan kesehatan maupun promosi kesehatan agar masyarakat lebih peka dalam pemanfaatan tanaman lokal yang ada disekitar, serta promosi kesehatan dapat di berikan melalui social media, lefleat, poster dan masih banyak lagi.

\section{DAFTAR PUSTAKA}

Adi, G. S. (2019). Pengaruh breastcare dan air seduhan daun kelor terhadap produksi asi. Pengaruh Breastcare Dan Air Seduhan Daun Kelor Terhadap Produksi ASI, 9(1), 76-99.

Indri Pratiwi, M. S. (2020). Pengaruh Pemberian Puding Daun Kelor (Moringa oleifera) terhadap Produksi Air Susu Ibu (ASI) pada Ibu Menyusui di Wilayah Kerja Puskesmas Kelurahan Cawang Jakarta Timur The. Jurnal Kesehatan Indonesia, XI(1).

Karima, N., Pratama, M. R., Berawi, K. N., Fisiologi, B., Kedokteran, F., Lampung, U., Kedokteran, F., \& Lampung, U. (2019). Potensi Biji Fenugreek 
Trigonella Foenum-Graecum L . ) Sebagai Terapi Komplementer dalam Meningkatkan Produksi Air Susu Ibu ( ASI ) Potential Fenugreek Seed ( Trigonella Foenum-Graecum L .) as an Complementary Therapy to Increases Breast Milk Production. Jurnal Kedokteran Universitas Lampung, 8(1), 261-267.

Kemenkes. (2018). info DATIN (Pusat Data dan Informasi Kementrian RI). Kementerian Kesehatan RI, 1-7.

Kemenkes. (2019). Profil Kesehatan Indonesia Tahun 2019. In Kementrian Kesehatan Repoblik Indonesia (Vol. 42, Issue 4).

Kementrian Kesehatan Republik Indonesia. (2019). Angka Kecukupan Gizi2019. Menteri Kesehatan Republik Indonesia Peraturan Menteri Kesehatan Republik Indonesia, Nomor 65(879), 2004-2006.

Kristina, N. N., \& Siti, F. S. (2014). Pemanfaatan tanaman kelor (Moringa oleifera) untuk meningkatkan produksi air susu ibu. In Warta Penelitian dan Pengembangan Tanaman Industri (Vol. 20, Issue 3, p. 27).

Mufdillah, Subijanto, Sutisna, E. \&, \& Akhyar, M. (2017). Buku Pedoman Pemberdayaan Ibu Menyusui pada Program ASI Ekslusif. Peduli ASI Ekslusif, 0-38.

Mustika, Nurjanah, U. (2018). Buku Ajar Asuhan Kebidanan Nifas. In semarang.

Okinarum, G. Y., Lestariningsih, L., \& Dewi, D. P. (2020). jantung pisang batu ( Musa balbisiana L . A . Colla ) untuk meningkatkan volume ASI Potency of cookies substituted with fenugreek ( Trigonella foenum - graecum ) and banana blossom ( Musa balbisiana L . A - Colla ) flour to increase breastmilk volume. Ilmu Gizi Indonesia, 03(02), 135-144.

Presiden Republik Indonesia. Peraturan Pemerintah Republik Indonesia Nomor
33 Tahun 2012 Tentang Pemberian Air Susu Ibu Ekslusif. Presiden RI: Jakarta.2012

Zakaria, Z., Hadju, V., As’ad, S., \& Bahar, B. (2016). Pengaruh Pemberian Ekstrak Daun Kelor Terhadap Kuantitas Dan Kualitas Air Susu Ibu (Asi) Pada Ibu Menyusui Bayi 0-6 Bulan. Media Kesehatan Masyarakat Indonesia Universitas Hasanuddin, 12(3), 161169. 